\title{
Evidence of the effect of dipyrone on the central nervous system as a determinant of delayed gastric emptying observed in rats after its administration
}

E.F. Collares and A.M. Vinagre
Departamento de Pediatria, Núcleo de Medicina e Cirurgia Experimental e Centro de Investigação em Pediatria, Faculdade de Ciências Médicas, Universidade Estadual de Campinas, Campinas, SP, Brasil

\section{Correspondence}

E.F. Collares

Departamento de Pediatria

FCM, UNICAMP

13083-970 Campinas, SP

Brasil

Fax: +55-19-3788-7322

E-mail: pediat@fcm.unicamp.br

Publication supported by FAPESP. ........................

Received July 29, 2002 Accepted May 21, 2003

\section{Abstract}

Dipyrone administered intravenously (iv) delays gastric emptying (GE) in rats. The objectives of the present study were to assess: 1) the effect of the dose of dipyrone and time after its $i v$ administration on GE in rats, 2) the effect of subdiaphragmatic vagotomy $(\mathrm{VgX})$ and bilateral electrolytic lesion of the paraventricular nucleus (PVNX) on the delayed GE induced by the drug, and 3) the intracerebroventricular (icv) action of dipyrone and of one of its metabolites, 4-aminoantipyrine on GE. Male Wistar rats received saline labeled with phenol red intragastrically as a test meal. GE was indirectly assessed by the determination of percent gastric retention (GR) of the test meal $10 \mathrm{~min}$ after administration by gavage. Dipyrone delays GE in a dose- and time-dependent manner. Thirty minutes after the $i v$ administration of 80 $\mathrm{mg} / \mathrm{kg}$ dipyrone, the animals showed significantly higher GR (mean = $62.6 \%$ ) compared to those receiving vehicle (31.5\%). VgX and PVNX significantly reduced the $i v$ effect of $80 \mathrm{mg} / \mathrm{kg}$ dipyrone (mean \%GR: $\mathrm{VgX}=28.3 v s$ Sham $=55.5$ and $\mathrm{PVNX}=34.5 v s$ Sham = 52.2). Icv administration of $4 \mu \mathrm{mol}$ dipyrone caused a significant increase in GR $(54.1 \%)$ of the test meal 10 min later, whereas administration of $4 \mu \mathrm{mol} 4$-aminoantipyrine had no effect (34.4\%). Although the dipyrone dose administered $i c v$ was 16 times lower than that applied $i v$, for the same time of action (10 $\mathrm{min})$, the GR of animals that received the drug $i c v(54.1 \%)$ or $i v(54.5 \%)$ did not differ significantly. In conclusion, the present results suggest that the effect of dipyrone in delaying GE is due to the action of the drug on the central nervous system, with the participation of the PVN and of the vagus nerve.
Key words

- Gastric emptying

- Dipyrone

- Paraventricular nucleus

- Vagus nerve

\section{Introduction}

Gastric emptying is a complex process of orderly transfer of the gastric content to the small intestine resulting from the action of excitatory and inhibitory mechanisms that control the motor activity of the stomach, pylorus and duodenum (1). The enteric nervous system modulates the activity of muscle fibers in the proximal and distal stomach $(2,3)$. The central nervous system (CNS) participates in the control of gastric emptying 
through connections with the enteric nervous system via the vagus nerve and the sympathetic nervous system (2). The dorsal complex of the vagus is under the influence of higher structures such as the paraventricular nucleus (PVN) of the hypothalamus which may modify gastric emptying (4-7). Once gastric emptying is started, the process is modulated by inhibitory stimuli depending on the physicochemical characteristics of the food bolus which act on receptors located in the mucosa of the small intestine $(1,8)$. Meals that are practically of an inert nature such as physiological saline have a minimal effect on these receptors (9).

Several conditions are known in which gastric emptying is delayed or accelerated (10). Intravenous ( $i v$ ) dipyrone administered at high doses has been shown to cause delayed gastric emptying in rats (11), an effect confirmed by our group using saline solution as a test meal (12). This drug, first synthesized more than 80 years ago, is a pyrazolone derivative with analgesic and antipyretic activities due in part to the action of dipyrone itself or of its metabolites on the CNS (1316).

However, the site of action and the mechanisms involved in the delay of gastric emptying caused by dipyrone are unknown. On this basis, the objectives of the present study were to assess 1 ) the effect of $i v$ dipyrone on the gastric emptying of a saline meal in rats with respect to dose and time after its administration, 2) the effect of subdiaphragmatic vagotomy and electrolytic lesion of the PVN on this phenomenon, and 3) the effect of intracerebroventricular (icv) application of the analgesic and of one of its metabolites, 4-aminoantipyrine (AA), on the gastric emptying of the same test meal.

\section{Material and Methods}

The study was conducted on male Wistar rats weighing 250-300 g adapted to laboratory conditions over a period of two weeks.
The experimental protocols used in this study followed the recommendations of the Colégio Brasileiro de Experimentação Animal (COBEA, Brazilian College of Animal Experimentation). In all surgical procedures the animals were first sedated with an intraperitoneal (ip) injection of $75 \mathrm{mg} / \mathrm{kg}$ thiopental. After the surgical procedures the animals were kept in individual cages with free access to ration and water.

Solutions of dipyrone (Sigma, St. Louis, MO, USA) or of AA (Sigma) in sterile saline as a vehicle were prepared at the time for use and were protected from light. Equivalent volumes of vehicle were used to treat the controls.

For the dose-response study, $i v$ (via a tail vein) vehicle (0) and 10, 20, 40 and $80 \mathrm{mg} / \mathrm{kg}$ dipyrone were used and gastric emptying was determined $1 \mathrm{~h}$ later. To determine the response with respect to time after administration, different groups received vehicle or dipyrone, $80 \mathrm{mg} / \mathrm{kg}$, $i v$, and gastric emptying was determined 10, 30, 60 and 120 min after the injections.

The rats used to assess the participation of the vagus nerve in the phenomenon were submitted to subdiaphragmatic section of the ventral and dorsal branches of the nerve two weeks before the procedure. The Sham group consisted of rats submitted to sham surgery and the Naive group was not submitted to any procedure. Data for animals displaying severe gastric stasis two weeks after vagotomy were excluded from analysis.

To assess the participation of the PVN, the animals were again divided into three groups: Naive, Sham and with limited bilateral PVN lesions (PVNX group). Ten days before the study PVNX animals were submitted to bilateral lesion with a current of 0.5 $\mathrm{mA}$ at two sites for $10 \mathrm{~s}$ using a nickel/ chromium electrode $0.25 \mathrm{~mm}$ in diameter covered with insulating resin except for 0.1 $\mathrm{mm}$ at the tip. The following coordinates were used: anteroposterior (AP) -1.2 and $-1.5 \mathrm{~mm}$, lateral $\pm 0.5 \mathrm{~mm}$, and vertical 7.8 
and $8.0 \mathrm{~mm}$ at the points corresponding to the AP point. All measurements were made in relation to the bregma using the Paxinos and Watson atlas (17). The same coordinates were used for the Sham groups except for the vertical one, when depth was $7.5 \mathrm{~mm}$, with no passage of current. Naive animals suffered no intervention.

In both studies, vehicle or an $80 \mathrm{mg} / \mathrm{kg}$ dipyrone solution was injected $i v$ and gastric emptying was assessed $30 \mathrm{~min}$ after injection.

For the study of the effect of icv injections, two weeks before the experiment each animal was implanted into the right lateral ventricle with a $15-\mathrm{mm}$ long stainless steel cannula $(21 \mathrm{G})$ fixed to the skull with two screws held in place with self-polymerizing acrylic resin and an instant adhesive (cyanoacrylate ester). The coordinates for the implantation were: $\mathrm{AP}=-0.2 \mathrm{~mm}$, right lateral $=1.5 \mathrm{~mm}$, and vertical $=4.2 \mathrm{~mm}$. All measurements were made in relation to the bregma using the de Groot atlas (18) as reference. An internal cannula (28 G) connected to a $25-\mu 1$ Hamilton syringe by a polyethylene tube was used for the icv microinjections, which consisted of $10 \mu \mathrm{l}$ saline or an equal volume of a solution containing $4 \mu \mathrm{mol}(1333.2 \mu \mathrm{g})$ dipyrone or $4 \mu \mathrm{mol}(812.8 \mu \mathrm{g})$ AA. These amounts had been established in preliminary studies. Gastric emptying was assessed 10 min after icv injections.

Gastric emptying was studied in awake animals between 14:00 and 17:00 $\mathrm{h}$ after 20 $h$ of fasting, with free access to water, which was interrupted at the time of the test. The test meal consisted of $2 \mathrm{ml} / 100 \mathrm{~g}$ body weight of an aqueous solution of $0.9 \% \mathrm{NaCl}$ containing $6 \mathrm{mg} / \mathrm{dl}$ phenol red as a marker. In all experiments, gastric emptying was assessed indirectly by the determination of percent gastric retention of phenol red in the test meal recovered from the gastric content 10 min after administration of the test meal by gavage (19). Phenol red concentrations were read with a spectrophotometer at $560 \mathrm{~nm}$.

After the experiments, all animals were sacrificed. In the PVNX group the brain was removed, fixed and embedded in paraffin and histological sections were obtained and stained with toluidine blue. For confirmation of the site of lesions, the sections were compared to the figures of the Paxinos and Watson atlas (17) under the microscope. In the animals with a cannula implanted into the lateral ventricle, the site was located by $i c v$ injection of $10 \mu 11 \%$ Evans blue at the end of the study of gastric emptying. In this group, after sacrifice the brain was removed, fixed in $10 \%$ formalin and sectioned and the $i c v$ injection was confirmed when the stain was found in the fourth ventricle.

The results of gastric emptying are reported as means \pm SEM. Data were analyzed statistically by ANOVA followed by the Tukey test for pair comparison $(\alpha=0.01)$.

\section{Results}

Gastric retention was significantly increased in animals that received dipyrone at the doses of 40 and $80 \mathrm{mg} / \mathrm{kg}$ compared to control (Figure 1), with a significant positive correlation $(\mathrm{r}=0.96)$. Also, at the dose of 80 $\mathrm{mg} / \mathrm{kg}$, gastric retention of the test meal was increased at times 10, 30 and $60 \mathrm{~min}$ compared to the respective controls, with a significant reduction of the effect at $120 \mathrm{~min}$ (Figure 2). These results confirm the reports

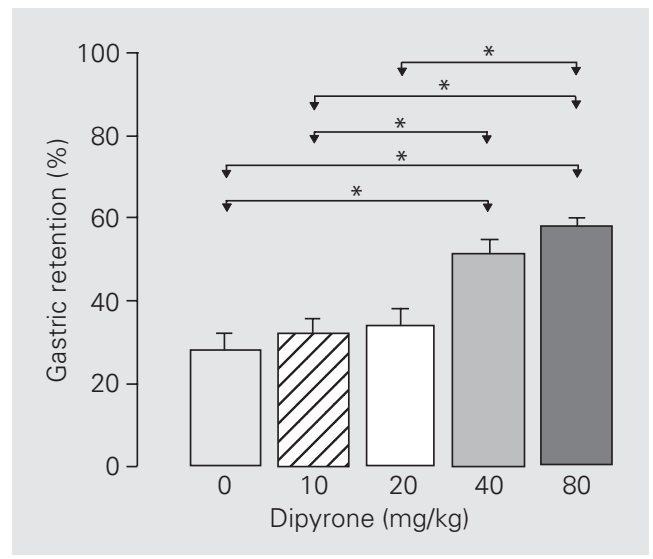

Figure 1. Gastric retention (\%), reported as mean \pm SEM, of a saline test meal determined 10 min after administration to rats by gavage. The animals $(\mathrm{N}=5)$ received iv vehicle (0) or dipyrone $(10,20,40$ and $80 \mathrm{mg} / \mathrm{kg})$ 60 min before the determination of gastric retention. ${ }^{*} \mathrm{P}<0.01$ for the comparisons indicated by the arrows (Tukey test). 


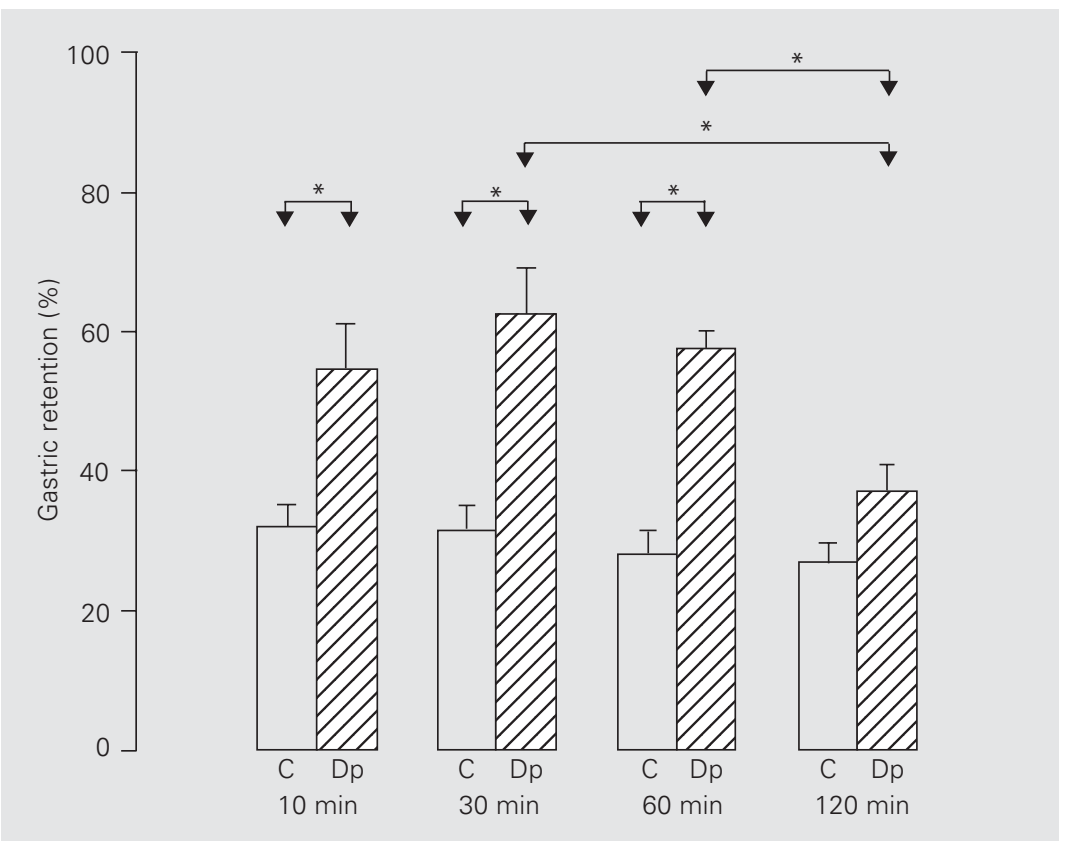

Figure 2. Gastric retention (\%), reported as mean \pm SEM, of a saline test meal determined $10 \mathrm{~min}$ after administration to rats by gavage. The animals $(N=5)$ received iv vehicle $(C)$ or $80 \mathrm{mg} / \mathrm{kg}$ dipyrone (Dp) 10,30,60 and $120 \mathrm{~min}$ before the determination of gastric retention. ${ }^{*} \mathrm{P}<0.01$ for the comparisons indicated by the arrows (Tukey test).

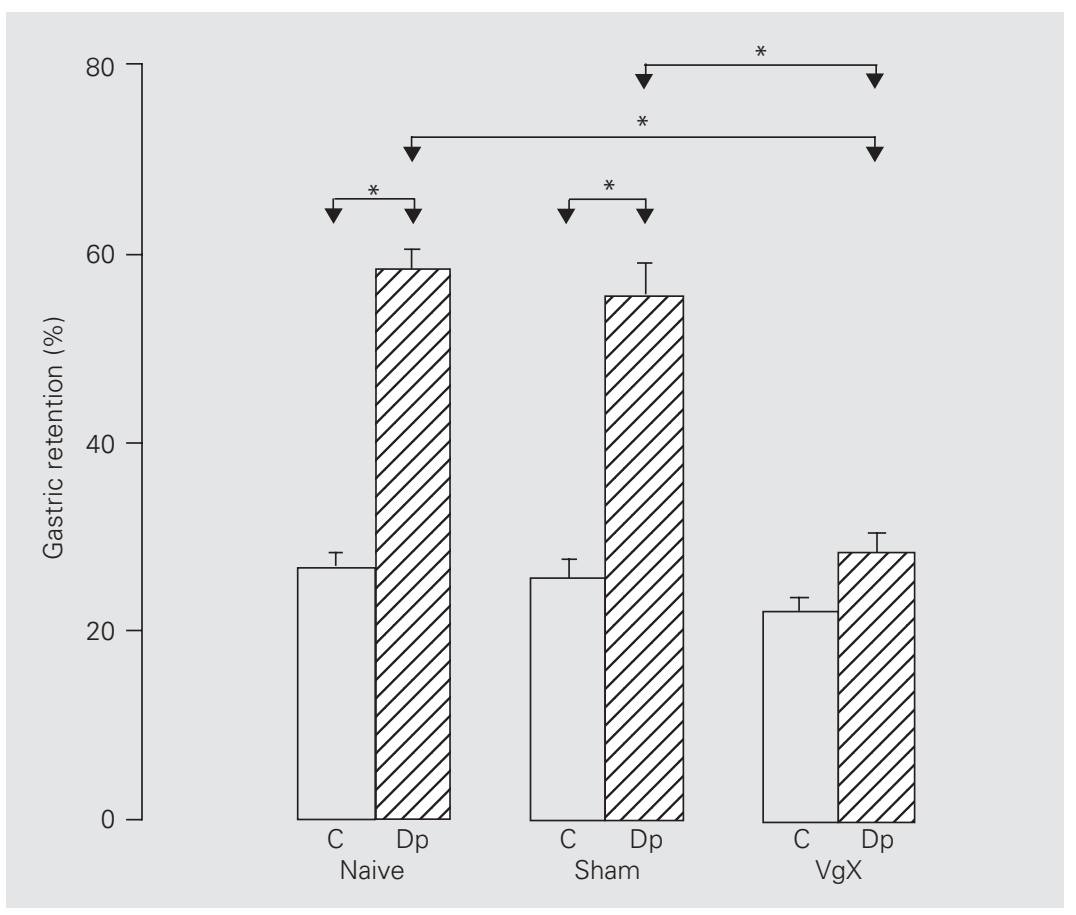

Figure 3. Gastric retention (\%), reported as mean \pm SEM, of a saline test meal determined $10 \mathrm{~min}$ after administration to rats by gavage. Two weeks before the procedure, the animals were submitted to sham surgery (Sham) or subdiaphragmatic vagotomy (VgX). The animals in the Naive group were not submitted to any procedure. The rats $(N=8)$ of each group received iv vehicle (C) or $80 \mathrm{mg} / \mathrm{kg}$ dipyrone (Dp) 30 min before the determination of gastric retention. ${ }^{*} \mathrm{P}<0.01$ for the comparisons indicated by the arrows (Tukey test). of others that high doses of dipyrone administered $i v$ delay gastric emptying and with the use of $80 \mathrm{mg} / \mathrm{kg}$ the effect is immediate and more intense during the first hour after administration.

In the study of the effect of vagotomy on the delay in gastric emptying caused by dipyrone (Figure 3), Sham and Naive animals, which received dipyrone, presented a significant increase in gastric retention of the meal compared to their controls. No significant differences were observed between these two groups when compared to the animals treated with dipyrone or vehicle. These data suggest that the surgical intervention did not interfere with the response of the animals to dipyrone. However, there was a significant reduction in gastric retention in the vagotomized animals which received dipyrone compared to Sham animals which also received the drug. There was no significant difference between vagotomized animals which received dipyrone or vehicle.

Figure 4 shows the location of electrolytic lesion and the effects of PVN lesion on the delay of gastric emptying induced by dipyrone. Observation and statistical analysis showed that the results were practically identical to those obtained in the preceding experiment. The Sham group did not differ from the Naive group, indicating that the surgical procedure did not interfere with the effect of dipyrone on gastric emptying. PVN lesion significantly reduced gastric retention in animals treated with dipyrone compared to similarly treated Sham animals. No significant differences were observed between Sham and PVNX animals that received vehicle or between PVNX animals that received vehicle or dipyrone.

When AA was administered icv, no significant effect on gastric retention of the meal was observed $10 \mathrm{~min}$ after application (Figure 5). On the other hand, dipyrone caused a significant increase in gastric retention compared to vehicle. When the effect of $i c v$ application of dipyrone on gastric reten- 

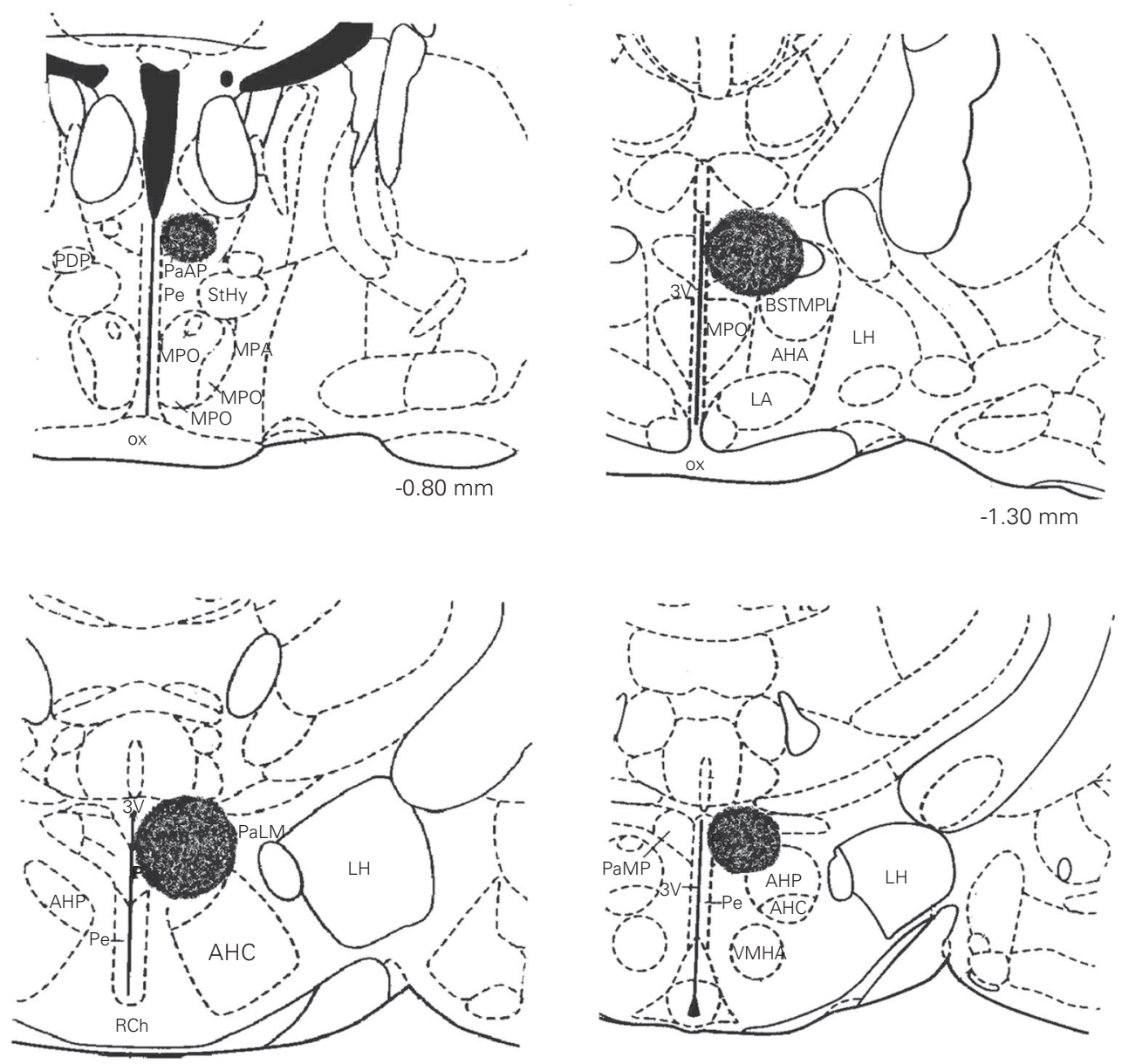

$-1.80 \mathrm{~mm}$

$-2.12 \mathrm{~mm}$

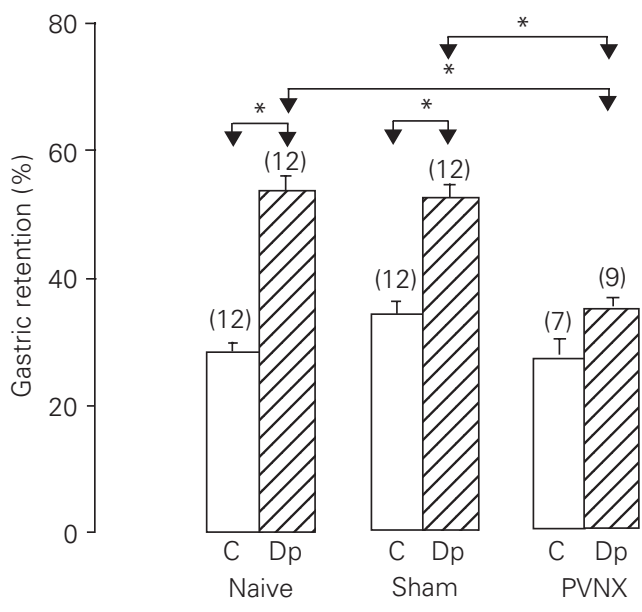

Figure 4. Top four panels are schematic presentations of the location of the electrolytic lesion in the hypothalamus. The numbers below each scheme indicate the rostrocaudal distance from the bregma. $3 \mathrm{~V}=3 \mathrm{rd}$ ventricle; $\mathrm{AHA}=$ anterior hypothalamic area, anterior part; $\mathrm{AHC}=$ anterior hypothalamic area, central part; $\mathrm{AHP}=$ anterior hypothalamic area, posterior part; BSTMPL = bed nucleus of stria terminalis, medial division, posterolateral part; LA = lateroanterior hypothalamic nucleus; $\mathrm{LH}=$ lateral hypothalamic area; MPA = medial preoptic area; $\mathrm{MPO}=$ medial preoptic nucleus; ox = optic chiasm; $\mathrm{PaAP}=$ paraventricular hypothalamic nucleus, anterior parvicellular part; $\mathrm{PaLM}=$ paraventricular hypothalamic nucleus, lateral magnocellular part; $\mathrm{PaMP}=$ paraventricular hypothalamic nucleus, medial parvicellular part; $P D P=$ posterodorsal preoptic nucleus; $\mathrm{Pe}=$ periventricular hypothalamic nucleus; $\mathrm{RCh}=$ retrochiasmatic area; $\mathrm{StHy}=$ striohypothalamic nucleus; $\mathrm{VMHA}=$ ventromedial hypothalamic nucleus, anterior part. The graph represents the gastric retention (\%), reported as mean \pm SEM, of a saline test solution $10 \mathrm{~min}$ after administration by gavage to the rats. Ten days before the procedure the animals were submitted to sham surgery (Sham) or to bilateral electroIytic lesion of the paraventricular nucleus of the hypothalamus (PVNX). The animals in the Naive group were not submitted to any intervention. Thirty minutes before evaluation of gastric emptying, the animals received vehicle (C) or $80 \mathrm{mg} / \mathrm{kg}$ dipyrone (Dp) iv. The number of animals is given in parentheses. ${ }^{*} \mathrm{P}<0.01$ for the comparisons indicated by the arrows (Tukey test). 
Figure 5. Gastric retention (\%), reported as mean \pm SEM, of a saline test meal determined 10 min after administration to rats by gavage. Two weeks before the procedure, a metal tube was implanted into the right lateral ventricle of each rat. The animals received icv $10 \mu$ of vehicle (C) or an equal volume of solution containing $4 \mu \mathrm{mol}$ (1333.2 $\mu \mathrm{g}$ ) dipyrone $(\mathrm{Dp})$ or 4 umol $(812.8 \mu \mathrm{g})$ 4-aminoantipyrine (AA) and gastric retention was determined $10 \mathrm{~min}$ after the icv injection. The number of animals is given in parentheses. ${ }^{*} \mathrm{P}<0.01$ for the comparisons indicated by the arrows (Tukey test).

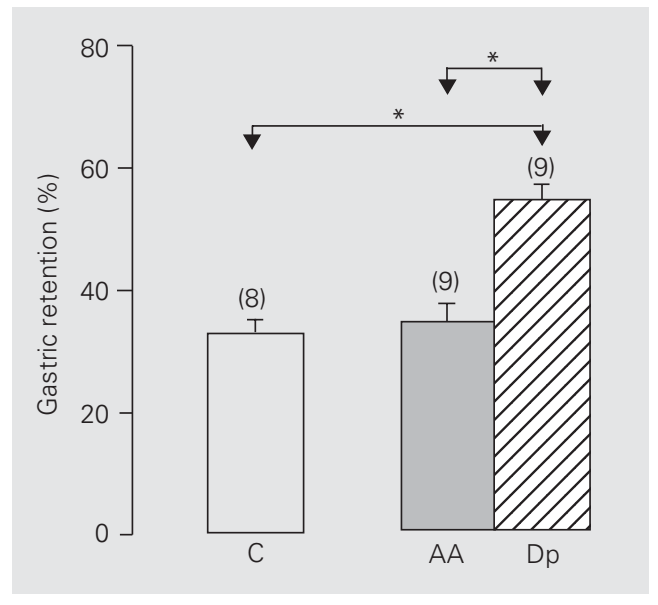

tion was compared with that of $i v$ application of the drug at the dose of $80 \mathrm{mg} / \mathrm{kg}$ body weight $10 \mathrm{~min}$ after administration (Figure 2 ), no significant difference was observed $(\mathrm{P}>0.05)$. The dipyrone dose applied icv was 16 times lower $(\sim 5 \mathrm{mg} / \mathrm{kg})$ than that applied $i v$.

\section{Discussion}

In addition to the known analgesic and antipyretic properties of dipyrone, we describe in the present study an unusual effect of the drug, i.e., a delay of gastric emptying in rats, confirming a previous report (11). It was demonstrated that this effect is dose dependent, occurs early and is more intense during the first hour after $i v$ administration (Figures 1 and 2). The relationship between this effect and the analgesic and antipyretic properties of the drug is unknown.

Dipyrone administered by the oral route is rapidly hydrolyzed by gastric juice, forming 4-methylaminoantipyrine (MAA), and is fully absorbed in this form (16). MAA is demethylated directly to AA mainly in the liver, and AA is later metabolized to 4acetylaminoantipyrine (AAA) and 4-formylaminoantipyrine (FAA). FAA may also be a direct product of MAA metabolism. Other metabolites are then generated from MAA, AA and AAA $(16,20)$. The hepatic isoen- zymes of cytochrome P450 that participate in these metabolic processes have not been identified, although there are indications that enzymes of the CYP2B family may be involved in rats $(16,21)$.

Dipyrone is considered to be a "pro-drug" acting through MAA and AA on the inhibition of prostaglandin synthesis, while the other two metabolites, AAA and FAA, are practically inactive $(13,14,16)$. After dipyrone administration, these metabolites detected in blood and in spinal fluid are excreted into urine during the first $24 \mathrm{~h}(14,16,22)$.

The mechanisms involved in the analgesic and antipyretic effect of dipyrone are poorly known and there is controversy about the sites of action of the drug. It has been proposed that this drug interferes with nociceptive and pyrexia mediators through the MAA and AA metabolites, blocking the synthesis of prostaglandins in the CNS (15). However, there are indications that it also induces analgesia by acting on peripheral nociceptive nerve endings through the generation of nitric oxide $(23,24)$. More recently, evidence has been reported showing that the antinociceptive effect of dipyrone occurs both at the peripheral and at the central level (25).

Dipyrone has a proven effect and is extensively used for the control of pain crises with a component of smooth muscle spasm (16). On this basis, a first hypothesis to explain the phenomenon of delayed gastric emptying could be that this effect is due to a direct action of the drug or of its metabolites on smooth muscle fibers and/or the enteric nervous system of the stomach and/or duodenum. However, preliminary studies on the direct action of dipyrone using isolated preparations demonstrated a discrete or absent effect of the drug on smooth muscle (26-28).

In addition, the present observation that the effect on gastric emptying was abolished by vagotomy (Figure 3 ) makes this possibility unlikely. Vagotomy modifies the motor activity of the stomach, blocking the arrival 
of afferent inhibitory stimuli in the nucleus tractus solitarii and abolishing the efferent stimuli originating in the dorsal nucleus of the vagus $(2,10,29-31)$.

The present study also showed that the participation of the PVN is necessary for the effect of dipyrone on gastric emptying since bilateral electrolytic lesion of the hypothalamic region corresponding to this nucleus abolished the effect of the drug (Figure 4). The cells of the parvocellular division of the PVN have connections with the nucleus tractus solitarii and the dorsal nucleus of the vagus (32-35). Under non-physiological conditions such as stress, this region of the hypothalamus interferes with gastric motility leading to delayed gastric emptying (4-6). On this basis, the results obtained thus far in the present study permit us to speculate that the PVN, because of the direct or indirect action of dipyrone or its metabolites, may affect gastric emptying through the vagus.

As shown in Figure 5, icv administration of dipyrone caused a significant gastric retention of the test meal 10 min later and equimolar application of AA by the same route had no effect. In contrast, when the two routes of administration ( $i c v$ and $i v$ ) were compared, gastric retention did not differ significantly after the use of an icv dose of dipyrone 16 times lower than that applied $i v$ for the same time of action (10 $\mathrm{min})$. A ratio of $1 / 10$ or more between the doses injected $i c v$ and $i v$ suggests that the drug has a direct action on the CNS (36). Favoring the possibility of a direct effect are observations of the analgesic action of dipyrone applied to the CNS $(37,38)$. In addition, there is the fact that dipyrone administered $i v$, in contrast to what occurs when it is administered per os, is metabolized more slowly, can be detected in the circulation for a very short period of time, is significantly excreted through the kidneys, and is detected in large quantities in the urine in the form of MAA $(16,39)$. Thus, we speculate that the drug, soon after injection, may reach the CNS and trigger the delay in gastric emptying.

However, since the icv effect of MAA was not tested, this metabolite, locally generated or reaching the CNS through the circulation, may be responsible for the effect on gastric emptying attributed to dipyrone. There is also the possibility that metabolites other than AA are responsible for this effect, since the isoenzymes P450IIB 1,2 associated with drug metabolism are found in the astrocytes of rats (40). However, this is speculative since there is no information about whether dipyrone is hydrolyzed in the CNS or whether there is a local generation or transformation of its metabolites.

The present results suggest that the delay in gastric emptying determined by dipyrone is due to the action of the drug on the CNS, with involvement of the PVN and participation of the vagus nerve.

\section{References}

1. Hunt JN (1983). Mechanisms and disorders of gastric emptying. Annual Review of Medicine, 34: 219-229.

2. Burks TF, Galligan JJ, Porreca F \& Barber WD (1985). Regulation of gastric emptying. Federation Proceedings, 44: 2897-2901.

3. Weisbrodt NW (1997). Gastric emptying. In: Johnson LR (Editor), Gastrointestinal Physiology. 5th edn. Mosby, St. Louis, 33-42.

4. Sakaguchi T \& Ohtake M (1985). Inhibition of gastric motility induced by activation of the hypotalamic paraventricular nucleus. Brain Research, 335: 365-367.

5. Mönnikes H, Schmidt BG, Raybould HE \& Taché Y (1992). CRF in the paraventricular nucleus mediates gastric and colonic response to restraint stress. American Journal of Physiology, 262: G137G143.

6. Collares-Buzato CB, Collares EF \& Fernandes GA (1993). Effect of paraventricular nucleus lesion and cold restraint stress on gastric emptying of a liquid meal in rats. Brazilian Journal of Medical and Biological Research, 26: 1009-1014.

7. Wood JD, Alpers DH \& Andrews PLR (1999). Fundamentals of neurogastroenterology. Gut, 45 (Suppl II): II-6-II-16.

8. Azpiroz F (1994). Control of gastric emptying by gastric tone. Digestive Diseases and Sciences, 39 (Suppl): 18s-19s.

9. Ehrlein HJ \& Akkermans LMA (1984). Gastric emptying. In: 
Akkermans LMA, Johnson AG \& Read NW (Editors), Gastric and Gastroduodenal Motility. Surgical Science Series 4, Praeger, New York, 74-84.

10. Camilleri M \& Malagelada J-R (1984). Gastric motility in disease. In: Akkermans LMA, Johnson AG \& Read NW (Editors), Gastric and Gastroduodenal Motility. Surgical Science Series 4, Praeger, New York, 201-232.

11. Rupp VS, Schroth HJ, Hildebrandt U, Garth H \& Feifel G (1987). Einfluss von Metamizol auf Magenentleerung und Dünndarmtransit bei der Ratte. Arzneimittel-Forschung (Drug Research), 37: 10511053.

12. Collares EF \& Vinagre AM (1998). Efeito da dipirona sobre o esvaziamento gástrico de ratos. XIII Annual Meeting of the Federação de Sociedades de Biologia Experimental, Caxambú, MG, Brazil, August 26-29, 175 (Abstract).

13. Weithmann KU \& Alpermann HG (1985). Biochemical and pharmacological effects of dipyrone and its metabolites in model systems related to the arachidonic acid cascade. Arzneimittel-Forschung (Drug Research), 35: 947-952.

14. Brogden RN (1986). Pyrazolone derivatives. Drugs, 32 (Suppl 4): 6070.

15. Shimada SG, Otterness IG \& Stitt JT (1994). A study of the mechanism of action of the mild analgesic dipyrone. Agents and Actions, 41: 188-192.

16. Levy M, Zylber-Katz E \& Rosenkranz B (1995). Clinical pharmacokinetics of dipyrone and its metabolites. Clinical Pharmacokinetics, 28: 216-234.

17. Paxinos G \& Watson C (1998). The Rat Brain in Stereotaxic Coordinates. 4th edn. Academic Press, San Diego.

18. de Groot T (1959). The Rat Forebrain in Stereotaxic Coordinates. NV Noord-Holandsch Witgevers, Amsterdam, The Netherlands.

19. Bucaretchi F \& Collares EF (1996). Effect of Phoneutria nigriventer spider venom on gastric emptying in rats. Brazilian Journal of Medical and Biological Research, 29: 205-211.

20. Geisslinger G, Böcker R \& Levy M (1996). High-performace liquid chromatographic analysis of dipyrone metabolites to study their formation in human liver microsomes. Pharmaceutical Research, 13: 1272-1275.

21. Kraul H, Pasanen M, Sigusch H, Stenbäck F, Park S-S, Gelboin HV \& Pelkonen O (1996). Immunohistochemical properties of dipyroneinduced cytochromes $\mathrm{P} 450$ in rats. Human Experimental Toxicology, 15: 45-50.

22. Cohen O, Zylber-Katz E, Caraco Y, Granit L \& Levy M (1998). Cerebrospinal fluid and plasma concentrations of dipyrone metabolites after a single oral dose of dipyrone. European Journal of Clinical Pharmacology, 54: 549-553.

23. Granados-Soto V, Flores-Murrieta FJ, Castañeda-Hernández G \& López-Muñoz FJ (1995). Evidence for the involvement of nitric oxide in the antinociceptive effect of ketorolac. European Journal of Pharmacology, 277: 281-284

24. Lorenzetti BB \& Ferreira SH (1996). Activation of the arginine-nitric oxide pathway in primary sensory neurons contributes to dipyroneinduced spinal and peripheral analgesia. Inflammation Research, 45: 308-311.
25. Mazario J \& Herrero JF (1999). Antinociceptive effects of metamizol (dipyrone) in rat single motor units. Neuroscience Letters, 274: 179182.

26. Alexander VK, Khreis A \& Traut G (1963). Das Zusammenwirken von Noramidopyrin-methansulfonat mit Cholin und Acetylcholin. Arzneimittel-Forschung (Drug Research), 13: 493-497.

27. Schiantarelli P, Murmann W \& Magi S (1979). Investigation of rociverine+dipyrone for antispasmodic and analgesic interactions. Arzneimittel-Forschung (Drug Research), 29: 760-765.

28. Hertle L \& Nawrath H (1984). Zur Wirkung von Baralgin auf isolierte Präparate des menschlichen oberen Harntraktes. Urologia Internationalis, 39: 84-90.

29. Wilbur BG \& Kelly KA (1973). Effect of proximal gastric, complete gastric, and truncal vagotomy on canine gastric electric activity, motility and emptying. Annals of Surgery, 178: 295-303.

30. McCann MJ \& Rogers RC (1992). Impact of antral mechanoreceptor activation on the vago-vagal reflex in the rat: Functional zonation of responses. Journal of Physiology, 453: 401-411.

31. Raybould HE \& Lloyd KCK (1994). Integration of postprandial function in the proximal gastrointestinal tract. Role of CCK and sensory pathways. Annals of the New York Academy of Sciences, 713: 143156.

32. Swanson LW \& Sawchenko PE (1980). Paraventricular nucleus: A site for the integration of neuroendocrine and autonomic mechanisms. Neuroendocrinology, 31: 410-417

33. Luiten PGM, Horst GJ ter, Karst H \& Steffens AB (1985). The course of paraventricular hypothalamic efferents to autonomic structures in medulla and spinal cord. Brain Research, 329: 374-378.

34. Lawrence D \& Pittman QJ (1985). Interaction between descending paraventricular neurons and vagal neurons. Brain Research, 332 158-160.

35. Kawano H \& Masuko S (1996). Neurons in the caudal ventrolateral medulla projecting to paraventricular hypothalamic nucleus receive synaptic inputs from the nucleus of solitary tract: a light and electron microscopic double-labeling study in the rat. Neuroscience Letters, 218: 33-36.

36. Bueno L (1996). Assessment of CNS control of gastrointestinal motility. In: Gaginella TS (Editor), Handbook of Methods in Gastrointestinal Pharmacology. CRC Press, Boca Raton, FL, 297-329.

37. Tortorici V, Vásquez E \& Vanegas H (1996). Naloxone partial reversal of the antinociception produced by dipyrone microinjected into the periaqueductal gray of rats. Possible involvement of medullary offand on-cells. Brain Research, 725: 106-110.

38. Jones SL (1996). Dipyrone into the nucleus raphe magnus inhibits the rat nociceptive tail-flick reflex. European Journal of Pharmacology, 318: 37-40

39. Asmardi G \& Jamali F (1985). Pharmacokinetics of dipyrone in man: role of the administration route. European Journal of Drug Metabolism and Pharmacokinetics, 10: 121-125.

40. Kempermann G, Knoth R, Gebicke-Haeter PJ, Stolz B-J \& Volk B (1994). Cytochrome P450 in rat astrocytes in vivo and in vitro: Intracellular localization and induction by phenytoin. Journal of Neuroscience Research, 39: 576-588. 